\title{
Running, walking, and hyperventilation causing asthma in children
}

\author{
H KILHAM, M TOOLEY, AND M SILVERMAN
}

From the Department of Paediatrics, Hammersmith Hospital, London W12 OHS, UK

\begin{abstract}
To examine further the relation between type of exercise, workload, ventilation, and exercise-induced asthma, we compared treadmill walking with treadmill running and treadmill running with isocapnic hyperventilation in separate studies in children and adolescents. Inspired air conditions were identical during each pair of tests. Walking and running with similar minute ventilation and oxygen consumption were followed by similar falls in peak expiratory flow rate as were running and hyperventilation with similar minute ventilation and end-tidal carbon dioxide tension. This study supports the concept that hyperventilation is a central mechanism in exercise-induced asthma.
\end{abstract}

It has been suggested that different forms of exercise cause different degrees of bronchospasm in subjects susceptible to exercise-induced asthma (EIA), with free-range running, treadmill running, cycling, walking, and swimming in approximately diminishing order of effect (Anderson et al, 1971; Fitch and Morton, 1971; Anderson, 1972; Silverman and Anderson, 1972a). The reasons for this are unclear. Previous studies in children have shown treadmill running to cause more bronchospasm than treadmill walking, even when workload was well matched during the comparisons (Silverman, 1973; Eggleston and Guerrant, 1976; James et al, 1976). A recent study in adults, however, showed no difference in the bronchial response to treadmill running compared to cycling, where oxygen consumption and duration of exercise were the same (Miller et al, 1975).

The fact that minute ventilation was well matched during, for instance, comparisons between swimming and running exercise (Anderson, 1972) lead to doubt about the importance of hyperventilation in the mechanism of EIA. Yet an early study showed bronchospasm could be precipitated by isocapnic hyperventilation in some asthmatic subjects (Chan Yeung et al, 1971), suggesting hyperventilation could be an important factor in EIA. Later studies showed minimal or variable bronchospasm from hyperventilation (Vassalo et al, 1972; McFadden et al, 1977); one of these studies used a rebreathing circuit to obtain isocapnia (McFadden et al, 1977). A recent study using a non-rebreathing circuit showed that isocapnic hyperventilation and hyperventilation from exercise produced similar degrees of airways obstruction (Zeballos et al, 1978 ). Other recent studies have shown a reduction in EIA with nose breathing as compared with mouth breathing (Shturman-Ellstein et al, 1978), the abolition of EIA by the inspiration of saturated air at body temperature (Chen and Horton, 1977), and the exacerbation of EIA by cold-air breathing during exercise (Strauss et al, 1977a). These observations imply that air conditions are crucial in the development of EIA and airways obstruction after hyperventilation.

We aimed to examine the relation between type of exercise, workload, ventilation, and induced asthma with two studies designed to reduce, as far as possible, the effects of environmental factors known to affect EIA.

\section{Patients and methods}

WALKING AND RUNNING

Eight boys and two girls, aged 11 to 17 years, performed a treadmill walking test and a treadmill running test on the same day. Anthropometric data and room temperature and relative humidity (Paper Hygrometer, Gallenkamp) at the start of each test are shown in table 1 . All subjects had asthma, as defined by Scadding (1966), and all had previously experienced EIA after treadmill running. No subject was being treated with systemic corticosteroids, and all other drugs were omitted for at least 12 hours before tests. Initial peak 
Table 1 Anthropometric data; inspired air temperature and relative humidity ( $R H)$

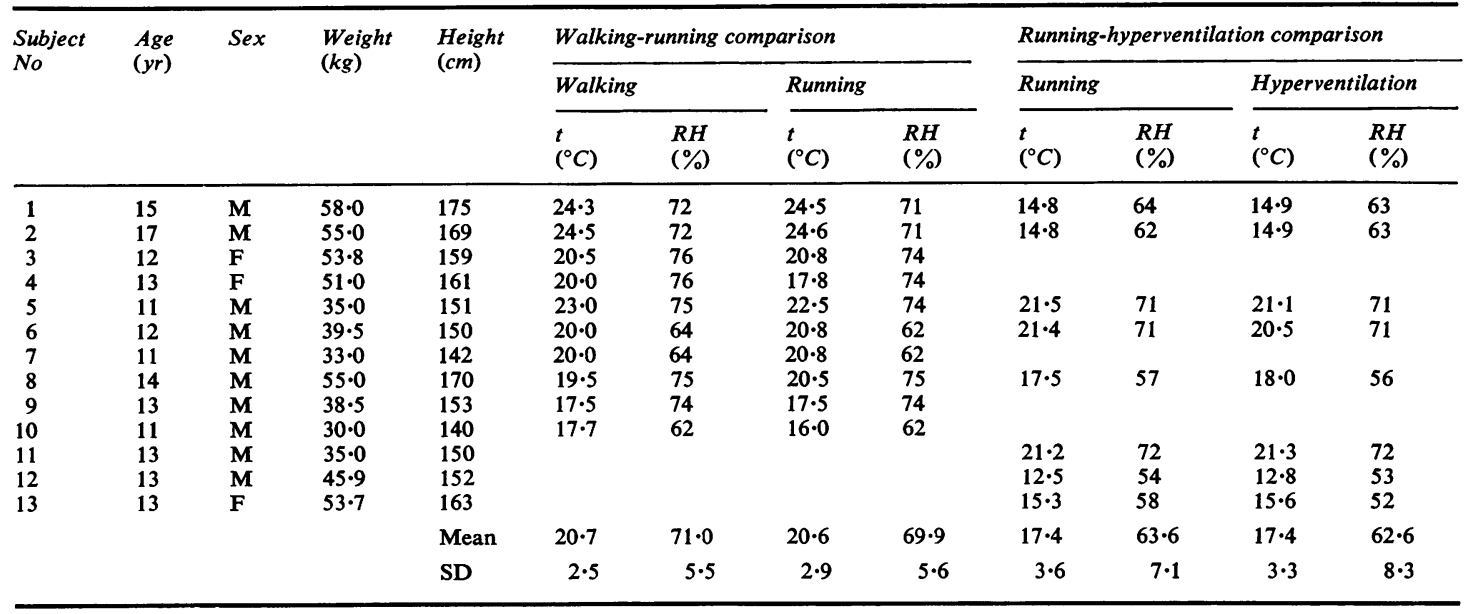

expiratory flow rates (PEFR) are shown, as percentage of expected normal values (Godfrey et al, 1970), in table 2 . The test order was randomly selected, and the periods of exercise separated by two-and-a-half hours, a period long enough to avoid the refractory period known to follow EIA (Edmunds et al, 1978) but short enough to avoid potentially considerable day-to-day changes in air temperature and relative humidity. Exercise tests consisted of six minutes of non-stop walking or running on a treadmill at $5 \cdot 3 \mathrm{kph}$. The treadmill slope was greater for the walking test, the aim being to achieve a similar oxygen consumption for each test, using the data of Silverman and Anderson (1972b) as a guide to the appropriate treadmill settings.

For two minutes before exercise, and during the whole exercise, the subjects wore a noseclip and breathed through a mouthpiece attached to a lowresistance, low dead-space $(50 \mathrm{ml})$ mobile valve. Inspired ventilation was measured with a dry gas meter (Parkinson Cowan CD 4), and the expired gas was mixed in a 41 chamber and continuously sampled for $\mathrm{CO}_{2}$ (measured by Godart infrared analyser) and $\mathrm{O}_{2}$ (Servomex paramagnetic analyser). The data, including ECG, were continuously recorded by an ink jet chart recorder (Mingograf 81) during each exercise test. The analysers were calibrated before and after each test, using gases of concentration chemically determined by the Haldane technique.

Airway function was tested by measuring PEFR with a Wright's meter, immediately before and 1 , $3,5,10,15$, and 20 minutes after exercise.

Table 2 Walking/running comparison: results

\begin{tabular}{|c|c|c|c|c|c|c|c|c|c|c|c|c|c|}
\hline \multirow{3}{*}{$\begin{array}{l}\text { Subject } \\
\text { No }\end{array}$} & \multirow{3}{*}{$\begin{array}{l}\text { First } \\
\text { test }\end{array}$} & \multicolumn{6}{|c|}{ Walking } & \multicolumn{6}{|c|}{ Running } \\
\hline & & \multicolumn{2}{|c|}{$\begin{array}{l}\text { Mean oxygen } \\
\text { consumption } \\
(\mathrm{ml} / \mathrm{min} / \mathrm{kg})\end{array}$} & \multicolumn{2}{|c|}{$\begin{array}{l}\text { Mean expired } \\
\text { ventilation } \\
(\text { l/min BTPS) }\end{array}$} & \multirow[t]{2}{*}{$\begin{array}{l}\text { Initial } \\
\text { PEFR } \\
\text { (\% of } \\
\text { expected) }\end{array}$} & \multirow[t]{2}{*}{$\begin{array}{l}\text { Fall in } \\
\text { PEFR } \\
(\%)\end{array}$} & \multicolumn{2}{|c|}{$\begin{array}{l}\text { Mean oxygen } \\
\text { consumption } \\
(\mathrm{ml} / \mathrm{min} / \mathrm{kg})\end{array}$} & \multicolumn{2}{|c|}{$\begin{array}{l}\text { Mean expired } \\
\text { ventilation } \\
(\text { l/min BTPS) }\end{array}$} & \multirow[t]{2}{*}{$\begin{array}{l}\text { Initial } \\
\text { PEFR } \\
\text { (\% of } \\
\text { expected) }\end{array}$} & \multirow[t]{2}{*}{$\begin{array}{l}\text { Fall in } \\
P E F R \\
(\%)\end{array}$} \\
\hline & & $\begin{array}{l}\text { Whole } \\
\text { test }\end{array}$ & $\begin{array}{l}\text { Last } \\
4 \mathrm{~min}\end{array}$ & $\begin{array}{l}\text { Whole } \\
\text { test }\end{array}$ & $\begin{array}{l}\text { Last } \\
4 \mathrm{~min}\end{array}$ & & & $\begin{array}{l}\text { Whole } \\
\text { test }\end{array}$ & $\begin{array}{l}\text { Last } \\
4 \mathrm{~min}\end{array}$ & $\begin{array}{l}\text { Whole } \\
\text { test }\end{array}$ & $\begin{array}{l}\text { Last } \\
4 \text { min }\end{array}$ & & \\
\hline \multirow[t]{3}{*}{$\begin{array}{r}1 \\
2 \\
3 \\
4 \\
5 \\
6 \\
7 \\
8 \\
9 \\
10\end{array}$} & $\begin{array}{l}\text { Walk } \\
\text { Walk } \\
\text { Run } \\
\text { Run } \\
\text { Walk } \\
\text { Walk } \\
\text { Run } \\
\text { Walk } \\
\text { Run } \\
\text { Run }\end{array}$ & $\begin{array}{l}29 \cdot 7 \\
26 \cdot 4 \\
23 \cdot 9 \\
25 \cdot 6 \\
27 \cdot 7 \\
29 \cdot 3 \\
31 \cdot 5 \\
30 \cdot 4 \\
27 \cdot 3 \\
26 \cdot 4\end{array}$ & $\begin{array}{l}31 \cdot 8 \\
28 \cdot 3 \\
25 \cdot 4 \\
28 \cdot 2 \\
30 \cdot 0 \\
32 \cdot 1 \\
35 \cdot 1 \\
32 \cdot 9 \\
29 \cdot 7 \\
28 \cdot 9\end{array}$ & $\begin{array}{l}54 \cdot 0 \\
37 \cdot 5 \\
32 \cdot 3 \\
38 \cdot 2 \\
30 \cdot 7 \\
33 \cdot 5 \\
31 \cdot 2 \\
37 \cdot 2 \\
26 \cdot 4 \\
23 \cdot 5\end{array}$ & $\begin{array}{l}57 \cdot 5 \\
41 \cdot 5 \\
35 \cdot 3 \\
42 \cdot 5 \\
34 \cdot 0 \\
36 \cdot 8 \\
35 \cdot 5 \\
42 \cdot 4 \\
29 \cdot 5 \\
25 \cdot 8\end{array}$ & $\begin{array}{r}74 \cdot 6 \\
101 \cdot 1 \\
58 \cdot 3 \\
100 \cdot 5 \\
43 \cdot 4 \\
67 \cdot 2 \\
60 \cdot 6 \\
60 \cdot 9 \\
86 \cdot 6 \\
75 \cdot 0\end{array}$ & $\begin{array}{l}63 \\
35 \\
54 \\
15 \\
55 \\
52 \\
63 \\
27 \\
51 \\
33\end{array}$ & $\begin{array}{l}29 \cdot 4 \\
27 \cdot 4 \\
26 \cdot 0 \\
27 \cdot 9 \\
30 \cdot 4 \\
29 \cdot 7 \\
28 \cdot 2 \\
29 \cdot 0 \\
30 \cdot 7 \\
28 \cdot 6\end{array}$ & $\begin{array}{l}31 \cdot 4 \\
29 \cdot 3 \\
28 \cdot 8 \\
32 \cdot 2 \\
32 \cdot 9 \\
32 \cdot 0 \\
30 \cdot 8 \\
30 \cdot 8 \\
32 \cdot 9 \\
30 \cdot 4\end{array}$ & $\begin{array}{l}50 \cdot 0 \\
42 \cdot 0 \\
40 \cdot 8 \\
44 \cdot 0 \\
33 \cdot 3 \\
32 \cdot 7 \\
25 \cdot 7 \\
35 \cdot 0 \\
29 \cdot 1 \\
27 \cdot 8\end{array}$ & $\begin{array}{l}50 \cdot 8 \\
45 \cdot 8 \\
46 \cdot 1 \\
50 \cdot 5 \\
36 \cdot 0 \\
36 \cdot 8 \\
27 \cdot 8 \\
38 \cdot 7 \\
32 \cdot 1 \\
29 \cdot 5\end{array}$ & $\begin{array}{l}70 \cdot 6 \\
97 \cdot 9 \\
74 \cdot 0 \\
89 \cdot 8 \\
46 \cdot 8 \\
73 \cdot 9 \\
80 \cdot 3 \\
60 \cdot 9 \\
90 \cdot 4 \\
62 \cdot 5\end{array}$ & $\begin{array}{l}54 \\
22 \\
67 \\
17 \\
58 \\
55 \\
70 \\
27 \\
36 \\
21\end{array}$ \\
\hline & Mean & $27 \cdot 8$ & $30 \cdot 2$ & $34 \cdot 5$ & $38 \cdot 1$ & $72 \cdot 8$ & $44 \cdot 8$ & $28 \cdot 7$ & $31 \cdot 2$ & $36 \cdot 0$ & $39 \cdot 4$ & $74 \cdot 7$ & $42 \cdot 7$ \\
\hline & SD & $2 \cdot 8$ & $2 \cdot 8$ & $8 \cdot 9$ & $8 \cdot 7$ & $18 \cdot 8$ & $16 \cdot 3$ & $1 \cdot 4$ & $1 \cdot 4$ & $7 \cdot 9$ & $8 \cdot 5$ & $15 \cdot 6$ & $20 \cdot 3$ \\
\hline
\end{tabular}


The results of tests on six other children were excluded for the following reasons: three children failed to develop EIA (defined as fall in peak flow of $15 \%$ or more) with either walking or running; one child developed severe asthma necessitating bronchodilator treatment after his first test; and in two tests essential data were unavailable because of difficulties with measuring or recording equipment.

\section{HYPERVENTILATION AND RUNNING}

Seven boys and one girl, aged 11 to 17 years, performed a treadmill running test and a voluntary isocapnic hyperventilation test on the same day. Anthropometric data and air conditions at the start of each test are shown in table 1. Subject selection and test procedure were similar to that described for the walking-running comparison, except that only end-tidal $\mathrm{CO}_{2}$ and inspired ventilation were measured during each six-minute exercise or voluntary hyperventilation period. As before, test order was randomly selected, and an interval of two-and-a-half hours was left between tests.

For two minutes before each test, and during the whole of each test, the subjects breathed through a valve as described above. During the voluntary hyperventilation test each subject was encouraged to hyperventilate to achieve a "target" minute ventilation and respiratory frequency, based on the values obtained during a previous treadmill running test. End-tidal $\mathrm{CO}_{2}$ was held constant by adding $100 \% \mathrm{CO}_{2}$ through a Rotameter flowmeter, at $0.4-1.51 / \mathrm{min}$, to the wide-bore corrugated respiratory line, $1.3 \mathrm{~m}$ from the valve. This did not produce measurable changes in inspired air temperature or relative humidity. PEFR was measured as for the walkingrunning comparison.

The "target" consisted of an electrically driven, continuously revolving pointer fixed over the dial of the gas meter, so that both the additional pointer and the hand of the gas meter could be easily seen by subjects. Subjects were asked to breathe in time to a metronome, with sufficient depth to match the rotation of the hand of the gas meter with that of the electrically driven pointer. Thus any target ventilation could be achieved merely by the setting of the additional pointer.

In the analysis of results, paired observations were compared using the $t$-test (for absolute values) or Wilcoxon's rank sum test (for percentages).

\section{Results}

WALKING AND RUNNING

Table 2 summarises the results of the walkingrunning comparison. In addition to the data shown, paired comparisons were made on air temperature and relative humidity, barometric pressure, heart rate during exercise, tidal volume, and absolute fall in PEFR (as opposed to percentage fall). No significant differences were found in any of the parameters examined. In addition there were no differences in initial PEFR or subsequent fall in PEFR between the first and second tests, or when running or walking was the first test performed.

In individual subjects during both walking and running, oxygen consumption and minute ventilation increased in a similar pattern over the first three minutes and tended to be stable over the last four minutes, though with greater variation in the sixth minute than in the third, fourth, and fifth minutes. While the additional oxygen consumption related to the exercise cannot be determined, it is thought that similar oxygen consumption between the two forms of exercise implies similar workload. Greater individual variations were noted with minute ventilation between the two forms of exercise, though mean values were similar, and there were no significant differences between walking and running. The initial PEF rates of $43-101 \%$ (mean $74 \%$ ) showed the subjects generally had mild to moderate asthma before testing, and falls in PEFR of 15$70 \%$ (mean $43 \%$ ) showed a pronounced, though not extreme, response to the level of exercise chosen.

\section{RUNNING AND HYPERVENTILATION}

Table 3 summarises the results of the runninghyperventilation comparisons. No significant differences were found between values of mean end-tidal $\mathrm{CO}_{2}$, mean inspired ventilation, initial PEFR, or fall in PEFR; respiratory frequency was greater during voluntary hyperventilation (P just $<0.05$ ). Though there were considerable individual variations in fall in PEFR between the two tests, mean values were similar, and there was no significant difference between running or voluntary hyperventilation (whether expressed as percentage fall or absolute fall in PEFR).

\section{Discussion}

WALKING AND RUNNING

We have shown that under identical environ- 
Table 3 Treadmill running/isocapnic hyperventilation comparison: results

\begin{tabular}{|c|c|c|c|c|c|c|c|c|c|c|c|}
\hline \multirow{2}{*}{$\begin{array}{l}\text { Subject } \\
\text { No }\end{array}$} & \multirow{2}{*}{$\begin{array}{l}\text { First } \\
\text { test }\end{array}$} & \multicolumn{5}{|l|}{ Running } & \multicolumn{5}{|c|}{ Hyperventilation } \\
\hline & & $\begin{array}{l}\text { Mean } \\
\text { Pet } \mathrm{CO}_{2} \\
(k P a)\end{array}$ & $\begin{array}{l}f \\
(l / \min )\end{array}$ & $\begin{array}{l}\text { Mean } \\
V_{1} \\
(l / \min \\
B T P S)\end{array}$ & $\begin{array}{l}\text { Initial } \\
\text { PEFR } \\
\text { (\% of } \\
\text { expected) }\end{array}$ & $\begin{array}{l}\text { Fall in } \\
P E F R \\
(\%)\end{array}$ & $\begin{array}{l}\text { Mean } \\
P e t \mathrm{CO}_{2} \\
(k P a)\end{array}$ & ${ }_{(l / \text { min })}$ & $\begin{array}{l}\text { Mean } \\
V_{1} \\
(\text { l/min } \\
\text { BTPS })\end{array}$ & $\begin{array}{l}\text { Initial } \\
\text { PEFR } \\
\text { (\% of } \\
\text { expected) }\end{array}$ & $\begin{array}{l}\text { Fall in } \\
P E F R \\
(\%)\end{array}$ \\
\hline $\begin{array}{r}8 \\
5 \\
6 \\
6 \\
11 \\
12 \\
2 \\
1 \\
13\end{array}$ & $\begin{array}{l}\text { Run } \\
\text { Hypervent } \\
\text { Hypervent } \\
\text { Run } \\
\text { Run } \\
\text { Hypervent } \\
\text { Hypervent } \\
\text { Run }\end{array}$ & $\begin{array}{l}4 \cdot 8 \\
4 \cdot 6 \\
5 \cdot 1 \\
5 \cdot 0 \\
5 \cdot 3 \\
5 \cdot 2 \\
4 \cdot 5 \\
4 \cdot 6\end{array}$ & $\begin{array}{l}22 \\
43 \\
51 \\
38 \\
37 \\
40 \\
38 \\
44\end{array}$ & $\begin{array}{l}37 \cdot 3 \\
26 \cdot 3 \\
22 \cdot 3 \\
32 \cdot 0 \\
49 \cdot 2 \\
52 \cdot 8 \\
60 \cdot 0 \\
58 \cdot 0\end{array}$ & $\begin{array}{r}58 \cdot 8 \\
50.0 \\
40.5 \\
117.0 \\
110.0 \\
98.0 \\
63.6 \\
78.0\end{array}$ & $\begin{array}{l}27 \cdot 0 \\
33 \cdot 3 \\
16 \cdot 7 \\
51 \cdot 0 \\
40 \cdot 0 \\
45 \cdot 6 \\
62 \cdot 5 \\
53 \cdot 0\end{array}$ & $\begin{array}{l}5 \cdot 1 \\
4 \cdot 9 \\
4 \cdot 3 \\
5 \cdot 0 \\
5 \cdot 0 \\
4 \cdot 4 \\
4 \cdot 5 \\
4 \cdot 7\end{array}$ & $\begin{array}{l}33 \\
55 \\
62 \\
44 \\
46 \\
49 \\
32 \\
78\end{array}$ & $\begin{array}{l}36 \cdot 2 \\
28 \cdot 4 \\
19 \cdot 8 \\
35 \cdot 5 \\
50 \cdot 5 \\
55 \cdot 5 \\
49 \cdot 2 \\
50 \cdot 0\end{array}$ & $\begin{array}{r}54 \cdot 6 \\
48 \cdot 5 \\
40 \cdot 5 \\
115 \cdot 0 \\
105 \cdot 5 \\
98 \cdot 0 \\
75 \cdot 5 \\
83 \cdot 5\end{array}$ & $\begin{array}{l}46 \cdot 0 \\
43 \cdot 7 \\
30 \cdot 0 \\
47 \cdot 0 \\
43 \cdot 4 \\
46 \cdot 7 \\
65 \cdot 7 \\
18 \cdot 3\end{array}$ \\
\hline \multirow{2}{*}{13} & Mean & $4 \cdot 9$ & $39 \cdot 1$ & $42 \cdot 2$ & $77 \cdot 0$ & $41 \cdot 1$ & $4 \cdot 7$ & 49.9 & $40 \cdot 6$ & $77 \cdot 6$ & 42.6 \\
\hline & SD & 0.3 & $8 \cdot 3$ & $14 \cdot 7$ & $28 \cdot 5$ & 15.0 & 0.3 & $15 \cdot 2$ & $12 \cdot 6$ & $27 \cdot 7$ & 13.8 \\
\hline
\end{tabular}

On paired $t$ tests, no significant differences except for frequency $(0.05>P>0.01)$.

Key: $\mathrm{PetCO}_{2}=$ end tidal $\mathrm{PCO}_{2} ; \mathrm{f}=$ Frequency of breathing; $\mathrm{V}_{1}=$ Inspired minute ventilation.

mental conditions when the severity of exercise is closely matched, EIA is equally severe after running and walking exercise. These results differ from previous studies on this subject. Some investigators attempted to standardise workload using heart rates without measurement of ventilation or oxygen consumption (Eggleston and Guerrant, 1976; James et al, 1976). Eggleston and Guerrant (1976) used a longer period of walking than of running, and workload and ventilation for the two forms of exercise were probably not comparable. In another walking versus running comparison with five subjects significantly greater airways obstruction occurred after running, despite achieving similar values of expired ventilation and oxygen consumption over the last minute of exercise (Silverman, 1973). Our study suggests the last minute of exercise may not be representative of the whole period of exercise, or even of the last four minutes of exercise during which oxygen consumption, expired ventilation, and other indices of workload are generally stable. In addition the subjects studied by Silverman (1973) performed running and walking tests on different days, so that variations in patient response, air temperature, and relative humidity could have led to different airway responses.

In a running versus cycling comparison in adults, Miller et al (1975) found no significant difference in airway response with matched total oxygen consumption, although the minute ventilation was not identical for the two forms of exercise. Possibly the level of energy expenditure with both forms of exercise was sufficient to provoke a maximal airway response in individual subjects at the time of testing.

Strauss et al (1977b) comparing arm and leg work, found greater EIA from arm work with a similar external workload, and proposed a relation between workload, muscle mass, and EIA. The explanation is probably the significantly higher ventilation found in their subjects during the arm work.

On the evidence currently available, it appears that different types of exercise produce similar degrees of EIA providing ventilation is similar, and provided that environmental conditions are similar. The differences between matched periods of exercise carried out in different environments (laboratory, open-air or heated swimming-pool) may possibly be due entirely to the local conditions of air temperature and humidity (Chen and Horton, 1977).

\section{RUNNING AND HYPERVENTILATION}

The results of our treadmill running versus isocapnic hyperventilation study are similar to the recently published study of Zeballos et al (1978), which compared treadmill walking and isocapnic hyperventilation. In contrast to our study testing was carried out on different days of the same week, periods of three and 10 minutes both of walking and hyperventilation were compared, a wide variety of respiratory function tests were done, though only once after exercise, and similar respiratory frequencies were achieved during both exercise and hyperventilation. In both studies rigorous attention was given to maintaining isocapnia in non-breathing circuits. Despite differences in design, both studies appear to confirm that isocapnic hyperventilation causes airways obstruction as severe as that produced by exercise performed at the same minute ventilation. Hyperventilation is probably the central mechanism in EIA.

Earlier reports of the airway response to volun- 
tary isocapnic hyperventilation varied, one study (Chan Yeung et al, 1971) showing consistent bronchospasm, while others showed variable (Vasallo et al, 1972) or minimal (Silverman, 1973) response. Some later studies, including that of McFadden et al (1977), showed no response to isocapnic hyperventilation. Recent studies have shown the importance of inspired air temperature and relative humidity in EIA, with reduction or abolition of EIA by warming and humidifying the inspired air (Chen and Horton, 1977; Strauss et al, 1978). The same phenomenon would appear to apply in hyperventilation-induced asthma, explaining the negative response to hyperventilation where partial rebreathing of expired air was used to maintain the $\mathrm{PCO}_{2}$ during hyperventilation (Silverman, 1973; McFadden et al, 1977).

Moreover, a correlation has been shown between respiratory heat and water loss from increased ventilation and the severity of EIA (Chen and Horton, 1977; Strauss et al, 1978). The exact sites of the receptors and the subsequent mediating mechanisms remain to be elucidated, although oropharyngeal epithelial receptors probably play an important part (Shturman-Ellstein et al, 1978). The confirmation of an important oropharyngeal reflex mechanism in asthma is obviously of great importance, opening up new avenues for the prophylaxis and treatment of asthma.

\section{References}

Anderson, S D (1972). Physiological aspects of exercise-induced bronchoconstriction. $\mathrm{PhD}$ thesis, University of London.

Anderson, S D, Connolly, N M, and Godfrey, S (1971). Comparison of bronchoconstriction induced by cycling and running. Thorax, 26, 396-401.

Chan-Yeung, $\mathbf{M} \mathbf{M}$ W, Vyas, $\mathbf{M} \mathbf{N}$, and Grzybowski, $S$ (1971). Exercise-induced asthma. American Review of Respiratory Disease, 104, 915-923.

Chen, W Y, and Horton, D J (1977). Heat and water loss from the airways and exercise-induced asthma. Respiration, 34, 305-313.

Edmunds, A T, Tooley, M, and Godfrey, S (1978). The refractory period after exercise-induced asthma. Its duration and relation to the severity of exercise. American Review of Respiratory Disease, 117, 247-254.

Eggleston, P A, and Guerrant, J L (1976). A standardised method of evaluating exercise-induced asthma. Journal of Allergy and Clinical Immunology, 58, 414-425.

Fitch, K D, and Morton, A R (1971). Specificity of exercise in exercise-induced asthma. British Medical Journal, 4, 577-581.

Godfrey, S, Kamburoff, P L, and Nairn, J R (1970). Spirometry, lung volumes and airway resistance in normal children aged 5-18 years. British Journal $\stackrel{?}{\circ}$ of Diseases of the Chest, 64, 15-24.

James, L, Faciane, J, and Sly, R M (1976). Effect of $\frac{\bar{c}}{\bar{c}}$ treadmill exercise on asthmatic children. Journal of $\overrightarrow{\mathbb{D}}$ Allergy and Clinical Immunology, 57, 408-416.

McFadden, E R jun, Stearns, D S, Ingram, $R$ H jun, ڤึ and Leith, D E (1977). Relative contributions of $\vec{\circ}$ hypocarbia and hyperpnea as mechanisms in post- $?$ exercise asthma. Journal of Applied Physiology: $\overrightarrow{\vec{\omega}}$ Respiratory, Environmental and Exercise Physiology, $\stackrel{\circ}{\circ}$ 42, 22-27.

Miller, G J, Davies, B H, Cole, T J, and Seaton, $\mathbf{A}_{\dot{\omega}}^{\stackrel{x}{\omega}}$ (1975). Comparison of the bronchial response to $\perp$ running and cycling in asthma using an improved ir definition of the response to work. Thorax, 30, 品 306-311.

Scadding, J G (1966). Patterns of respiratory in- 을 sufficiency. Lancet, 1, 701-705.

Shturman-Ellstein, R, Zeballos, R J, Buckley, J M, and Souhrada, J F (1978). The beneficial effect of $\overrightarrow{0}$ nasal breathing on exercise-induced broncho- $\mathbb{D}$ constriction. American Review of Respiratory Disease, 118, 65-73.

Silverman, M (1973). Exercise studies on asthmatic 6 children. MD thesis, University of Cambridge.

Silverman, M, and Anderson, S D (1972a). The standardisation of exercise tests in asthmatic children. Archives of Disease in Childhood, 47, 882-889.

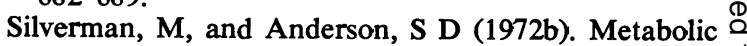
cost of treadmill exercise in children. Journal of $\overrightarrow{\vec{\sigma}}$ Applied Physiology, 33, 696-698.

Strauss, $R$ H, McFadden, E $R$ jun, Ingram, $R$ H jun, and Jaeger, J J (1977a). Enhancement of exercise-induced asthma by cold air. New England Journal of Medicine, 297, 743-747.

Strauss, R H, Haynes, R L, Ingram, R $\mathbf{H}$ jun, and McFadden, $E \mathrm{R}$ jun (1977b). Comparison of arm versus leg work in induction of acute episodes of asthma. Journal of Applied Physiology: Respiratory, Environmental and Exercise Physiology, 42, 565570.

Strauss, R H, McFadden, E R jun, Ingram, R H jun, 을 Deal, E C jun, Jaeger, J J, and Stearns, D (1978). I Influence of heat and humidity on the airway obstruction induced by exercise in asthma. Journal of Clinical Investigation, 61, 433-440.

Vassallo, C L, Gee, J B L, and Domm, B M (1972). N Exercise-induced asthma: observations regarding hypocapnia and acidosis. American Review of Respiratory Disease, 105, 42-49.

Zeballos, R J, Shturman-Ellstein, R, McNally, J F jun, Hirsch, J E, and Souhrada, J R (1978). The role of hyperventilation in exercise-induced bronchoconstriction. American Review of Respiratory Disease, 118, 877-884.

Requests for reprints to: Dr H Kilham, Royal Alexandra Hospital for Children, Box 34 PO, Camperdown 2050, NSW, Australia. 